\title{
Experiências vivenciadas em laboratório de análises clínicas de um hospital universitário
} Experiences in a clinical analysis laboratory of a university hospital

Experiencias en un laboratorio de análisis clínico en un hospital universitario Francisco Patricio de ANDRADE JÚNIOR ${ }^{1}$ Egberto Santos CARMO2

${ }^{1}$ Programa de Pós-Graduação em Produtos Naturais e Sintéticos Bioativos, área de concentração de Farmacologia, UFPB 58059-900 João Pessoa-PB, Brasil ${ }^{2}$ Centro de Educação e Saúde, Universidade Federal de Campina Grande, 58175-000 Cuité-PB, Brasil

\section{Resumo}

Introdução: As análises clínicas estão dentro das competências que podem ser desenvolvidas pelo profissional farmacêutico, em que este, por sua vez, necessita de conhecimentos teórico-práticos em diversas disciplinas, fazendo com que seja imprescindível o desenvolvimento de estágios para se poder atuar nesta área. Objetivo: Levando em consideração a importância que o estágio em análises clínicas e suas práticas apresentam para o futuro profissional farmacêutico, o presente trabalho teve por objetivo descrever as atividades realizadas durante o estágio obrigatório em análises clínicas. Materiais e métodos: Tratou-se de um estudo descritivo, do tipo relato de experiência, realizado entre junho a agosto de 2018, no Laboratório de Análises Clínicas do Hospital Universitário Alcides Carneiro. Resultados: No setor de urinálise, o estagiário deveria desenvolver junto ao farmacêutico a análise física, química e microscópica da urina, enquanto que no setor de bioquímica todas as análises eram semiautomatizadas, em que havia a análise de sangue, soro, plasma, líquor e urina. Em microbiologia o estagiário observava a coleta de diferentes materiais biológicos, semeava as amostras, fazia inóculos e utilizava-se de máquinas que permitiam a incubação, identificação e o perfil de sensibilidade dos microrganismos isolados. No setor de hematologia houve o desenvolvimento de atividades voltadas para microscopia, coloração de lâminas e análises semiautomatizadas. Na coleta, por sua vez, foram realizadas coletas de sangue venoso, tempo de coagulação e sangria. Conclusão: O estágio em análises clínicas se mostrou de grande importância ao graduando em farmácia, uma vez que, possibilitou por em prática os conhecimentos teóricos anteriormente adquiridos.

Descritores: Técnicas de Laboratório Clínico; Laboratórios Hospitalares; Apoio ao desenvolvimento de Recursos Humanos.

\section{Abstract}

Introduction: The clinical analysis are within the competencies that can be developed by the pharmaceutical professional, who, in turn, requires theoretical and practical knowledge in several disciplines, making it necessary to develop internships to be able to work in this area . Objective: This study aimed at describing the activities carried out during the compulsory training in clinical analysis, taking into account the importance of the clinical examination stage and its practices for the future pharmacist. Materials and methods: This was a descriptive, experience-type study carried out between June and August of 2018 at the Laboratory of Clinical Analysis of the University Hospital Alcides Carneiro. Results: In the urinalysis sector, the trainee should develop the physical, chemical and microscopic analysis of the urine, while in the biochemistry sector all analyzes were semi-automated, in which blood, serum, plasma, cerebrospinal fluid and urine. In microbiology the trainee observed the collection of different biological materials, seeded the samples, made inoculums and used machines that allowed the incubation, identification and sensitivity profile of the isolated microorganisms. In the hematology sector, the development of activities focused on microscopy, staining of slides and semi-automated analyzes were carried out. In the collection, in turn, venous blood collections, coagulation time and bleeding were performed. Conclusion: The stage in clinical analysis was of great importance to the graduate in pharmacy, since, made possible by putting into practice the theoretical knowledge previously acquired.

Descriptors: Clinical Laboratory Techniques; Laboratories, Hospital; Training Support.

\section{Resumen}

Introducción: Los análisis clínicos están dentro de las competencias que pueden ser desarrolladas por el profesional farmacéutico, en que éste, a su vez, necesita conocimientos teórico-prácticos en diversas disciplinas, haciendo que sea imprescindible el desarrollo de etapas para poder actuar en esta área. Objetivo: Tomando en consideración la importancia que la pasantía en análisis clínicos y sus prácticas presentan para el futuro profesional farmacéutico, el presente trabajo tuvo por objetivo describir las actividades realizadas durante la pasantía obligatoria en análisis clínicos. Materiales y métodos: Se trata de un estudio descriptivo, del tipo relato de experiencia, realizado entre junio a agosto de 2018, en el Laboratorio de Análisis Clínicos del Hospital Universitario Alcides Carneiro. Resultados: En el sector del urinálisis, el pasante debería desarrollar junto al farmacéutico el análisis físico, químico y microscópico de la orina, mientras que en el sector de bioquímica todos los análisis eran semi-automatizados, en que había el análisis de sangre, suero, plasma, líquido cefalorraquídeo y orina. En microbiología el pasante observaba la recolección de diferentes materiales biológicos, sembraba las muestras, hacía inóculos y se utilizaba de máquinas que permitían la incubación, identificación y el perfil de sensibilidad de los microorganismos aislados. En el sector de hematología hubo el desarrollo de actividades volcadas para microscopía, coloración de láminas y análisis semiautomáticos. En la colecta, a su vez, se realizaron colectas de sangre venosa, tiempo de coagulación y sangría. Conclusión: La pasantía en análisis clínicos se mostró de gran importancia al estudiante de farmacia, una vez que, posibilitó poner en práctica los conocimientos teóricos anteriormente adquiridos.

Descriptores: Técnicas de Laboratorio Clínico; Laboratorios de Hospital; Apoyo a la Formación Profesional.

\section{INTRODUÇÃO}

O curso de Bacharelado em Farmácia da Universidade Federal de Campina Grande (UFCG), tem por objetivo permitir uma formação generalista, humanística, crítica e reflexiva, dando assim suporte para que os profissionais formados por esta instituição sejam capazes de atuar em diversos níveis de atenção a saúde ${ }^{1}$.

Dentre as áreas em que o profissional farmacêutico pode atuar é possível destacar as Análises Clínicas em que o farmacêutico trabalha principalmente na realização e interpretação de exames laboratoriais, assim como, na emissão de laudos e pareces, e ainda se responsabiliza tecnicamente por análises clínico-laboratoriais ${ }^{2}$.
Dessa maneira, esse profissional necessita adquirir conhecimentos teórico-práticos de diversas áreas, destacando-se: bioquímica, parasitologia, imunologia, urinálise, hematologia, citologia, toxicologia, virologia, bacteriologia, micologia e biologia molecular.

Ademais, o farmacêutico que atua como analista em laboratórios de análises clínicas, apresenta um importante papel social e econômico, uma vez que, é o profissional responsável por dar suporte para um diagnóstico clínico mais correto e também permite a geração de dados epidemiológicos que contribuam para a geração de políticas públicas a nível institucional, municipal, estadual ou nacional ${ }^{4}$. 
Dessa forma, é importante que o estudante de Farmácia realize estágios para o desenvolvimento de habilidades pertinentes as análises clínicas, uma vez que, devido a abrangência de conhecimentos necessários, torna-se impraticável trabalhar com essa área sem ter nenhum tipo de experiência prévia. Contudo, a UFCG preconiza que para a realização do estágio em análises clínicas, o estudante deve escolher um único local para desenvolver as atividades, assim, a instituição elegida foi o Hospital Universitário Alcides Carneiro (HUAC).

O HUAC foi inaugurado em 20 de dezembro de 1950 e atualmente é vinculado a UFCG, havendo portanto, dentro do âmbito hospitalar, o desenvolvimento de atividades de ensino, extensão e pesquisa $^{5}$. Dentre as atividades de ensino, destaca-se a realização de estágios supervisionados que podem ser realizados em farmácia hospitalar ou no laboratório de análises clínicas. Em relação ao laboratório de análises clínicas do HUAC, mais especificamente, este é composto por diferentes setores, entretanto, de acordo com o que foi proposto para o desenvolvimento de atividades durante o período de estágio, os estagiários deveriam ter contato com os seguintes setores: Urinálise, Hematologia, Bioquímica, Microbiologia e Coleta.

Assim, levando em consideração a importância que o estágio em análises clínicas apresenta para o futuro profissional farmacêutico, o presente trabalho teve por objetivo descrever as atividades realizadas durante o estágio obrigatório em análises clínicas.

\section{MATERIAL E MÉTODO}

Trata-se de estudo descritivo, do tipo relato de experiência ${ }^{6}$, realizado entre junho a agosto de 2018, no Laboratório de Análises Clínicas do Hospital Universitário Alcides Carneiro.

\section{RESULTADOS E DISCUSSÃO}

No início da rotina laboratorial havia o processo de paramentação a partir do uso de Equipamentos de Proteção Individual (EPI) obrigatórios, utilizando-se principalmente jaleco, luvas, touca e máscara. Além disso, para poder realizar qualquer tipo de atividade no âmbito laboratorial era necessário que aqueles que adentrassem esse ambiente estivessem utilizando calça comprida e sapato fechado, para garantir maior proteção frente a possível contaminação com material biológico. Este procedimento foi adotado para todos os setores.

\section{○ Urinálise}

O setor de urinálise é o responsável por realizar o exame de urina/sumário de urina que apesar do baixo custo, possui impacto importante na saúde do paciente, uma vez que, falsos positivos podem acarretar em investigações adicionais e mais gastos ao Sistema Único de Saúde (SUS) ${ }^{7}$.
Neste setor, após a paramentação, era feita a assepsia das bancadas com o uso de álcool a $70 \%$ e hipoclorito de sódio, e as lâminas, pipetas, ponteiras, estantes, lamínulas, tiras reativas e papel toalha eram organizados sobre essas bancadas antes do início da jornada laboral, propriamente dita.

Em seguida, o material biológico era recolhido juntamente com as planilhas contendo informações sobre o paciente, como: nome completo, idade, sexo e quais foram os exames solicitados, a partir daí as amostras de urina eram conferidas e numeradas em sequência e depois agitadas para que fossem homogeneizadas e logo adicionadas aos tubos Falcon.

A análise da urina era realizada em três etapas distintas: análise física, química e microscópica. A análise física tratava-se da verificação das características visuais e olfativas da urina, como cor, odor e aspecto, enquanto que a análise química era realizada através de tiras-teste semiquantitativas ${ }^{8}$.

$\mathrm{Na}$ análise química, mais especificamente, era possível analisar o urobilinogênio, glicose, corpos cetônicos, proteína, bilirrubina, nitrito, $\mathrm{pH}$, sangue/hemoglobina, densidade e leucócitos. A detecção de qualquer um desses elementos na urina era feita através de modificações colorimétricas observadas na tira-teste.

Em seguida, os dados da análise físicoquímica eram computados e as amostras de urina eram levadas para a centrífuga, onde eram centrifugadas durante 5 minutos a $1500 \mathrm{rpm}$. O sobrenadante era desprezado, e $20 \mu \mathrm{L}$ da suspensão do sedimento era transferido para uma lâmina e depois adicionava-se uma lamínula para dar início a análise microscópica ${ }^{8}$.

$\mathrm{Na}$ análise microscópica utilizavam-se as objetivas de 10x e 40x, em que foi possível observar, quando presentes, hemácias, piócitos, muco, células epiteliais de descamação, leveduras, cilindros e cristais de ácido úrico, oxalato de cálcio mono e dihidratados, fosfatos amorfos, uratos amorfos e fosfatos de cálcio e Trichomonas vaginalis. Algumas dessas estruturas podem ser observadas abaixo (Figura 1).

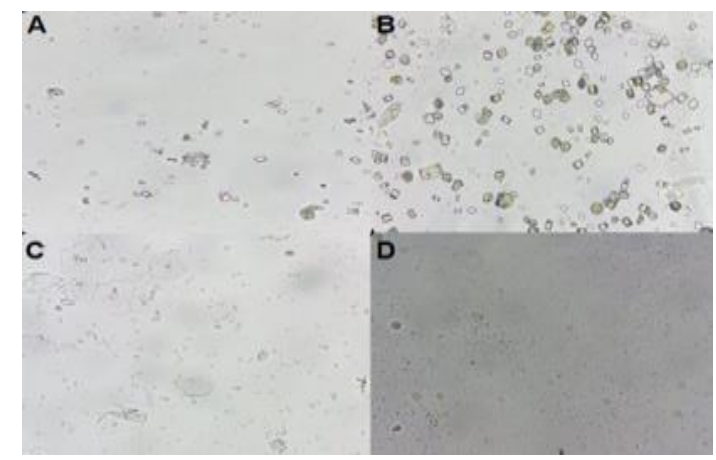

Figura 1: $\mathrm{A}=$ Cristais de oxalatado de cálcio; $\mathrm{B}=$ Cristais de ácido úrico; $\mathrm{C}=$ Células epiteliais de descamação e leveduras; $\mathrm{D}=$ Bactérias e piócitos. Fonte: Dados da pesquisa 
Durante o desenvolvimento das atividades neste setor, ainda foi possível a criação de um roteiro com imagens, o qual fosse útil para a identificação de diferentes cristais, ficando disponível no setor para outros profissionais e futuros estagiários.

Por fim, como última atividade realizada no setor de urinálise, pode-se destacar a pesquisa de sangue oculto em amostras fecais, através do método de imunocromatograma, que trata-se de um exame de baixo custo, usado como diagnóstico de triagem para pesquisa de carcinoma colo-retal em pacientes sintomáticos e é recomendada como forma preventiva para todo e qualquer paciente que possua mais de 40 anos de idade ${ }^{9,10}$.

$O$ teste era realizado da seguinte forma: inicialmente abria-se o frasco contendo a solução teste e fazia-se com que sua alça tivesse contato com três pontos distintos da amostra fecal. Entre um contato e outro, com a amostra, a alça era lavada junto a solução reagente permitindo que as fezes impregnadas a esta se dissolvessem. Em seguida, deveria haver agitação de forma rigorosa por cerca de 5 minutos. Após esse procedimento, por meio do conta gotas, duas gotas eram adicionadas ao cassete e esperava-se cerca de 5 minutos. Caso só houvesse o surgimento traço controle e o traço teste implicava em amostra reagente e o teste válido.

\section{- Bioquímica}

No setor de bioquímica, após a paramentação iniciava-se o processo de recolhimento de amostras de sangue, as quais eram disponibilizadas conforme a coleta ia sendo realizada pelos profissionais do setor de coleta ambulatorial, com mais de 100 amostras/dia.

As amostras eram armazenadas em tubos de tampa amarela e roxa. A de tampa amarela possuía ativador de coágulos, permitindo que o sangue coagulasse de forma mais rápida, enquanto que amostras advindas de tubos de tampa roxa, eram aquelas que possuíam EDTA, a fim de impossibilitar a coagulação ${ }^{11}$, sendo esta última utilizada para dosagem de dextrosol e hemoglobina glicada, uma vez que, para esse tipo de dosagem utiliza-se o sangue total. Outra possibilidade ainda era de que as amostras fossem advindas de pacientes internos, sendo impossível determinar a quantidade das mesmas.

Depois que as amostras encontravam-se coaguladas, eram levadas à centrifugação por 5 minutos a $2000 \mathrm{rpm}$, de forma que era possível separar o soro dos demais componentes sanguíneos. Em seguida, as amostras eram separadas conforme sua finalidade, uma parte para dosagens bioquímicas, outra para sorologias e as demais ficavam separadas em outras estantes, devido serem de pacientes internos ou para fins de glicemia pós prandial ou ainda hemoglobina glicada e dextrosol.

Logo após este processo, as amostras eram conferidas e levadas a máquina BA-400 para que fossem realizadas as análises bioquímicas, entretanto antes de adicionar o material biológico ao equipamento, este tinha de ser preparado. Inicialmente a máquina deveria ser ligada e o controle de qualidade aplicado, em que seguia-se como base a carta controle de Levey-Jennigs, que leva em consideração uma linha central média e linhas adjacentes contendo diferentes desvios padrões(DS) ${ }^{12}$.

Na Figura 2 é possível observar que os dois primeiros pontos encontravam-se foram do valor de 2DS, sendo portanto necessário reiniciar os testes depois de haver a correção do sistema analítico. Após a realização das correções evidencia-se que os pontos 3 e 4 apresentavam-se dentro do limite superior e inferior a 2 DS, estando portanto apto a realização das análises; para cada tipo de análise havia um controle de qualidade específico com um gráfico distinto para cada analito.

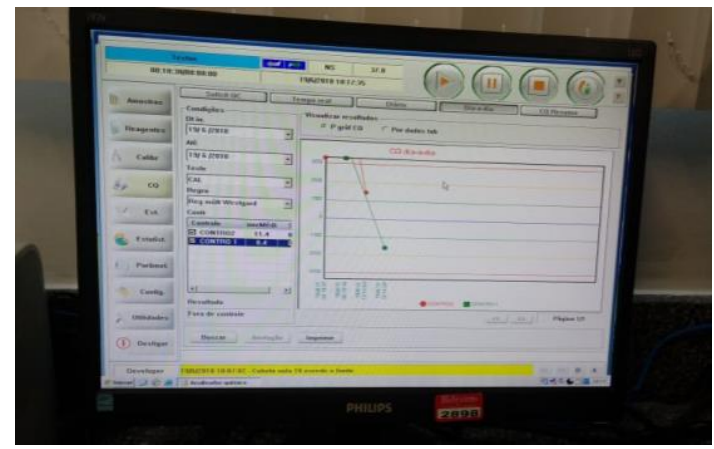

Figura 2: Representação do gráfico de Levey-Jennigs. Fonte: Dados da pesquisa

Paralelamente a checagem do controle de qualidade, a máquina era lavada automaticamente, entretanto, a água passava por tratamentos realizados a partir de osmose reversa. Desta maneira, tinha-se uma água com baixas concentrações de sais, sendo portanto, propícia para a realização das dosagens bioquímicas.

Depois de a água estar apta a lavagem da máquina e o equipamento estar devidamente limpo, as amostras eram adicionadas ao BA-400 que apresentava um sistema com agulhas e canalículos responsáveis por permitir pipetar as amostras e determinados reagentes para cada análise.

O BA-400 continha duas bandejas, uma para adição de reagentes e outra para as amostras, em que utilizava-se para a realização das dosagens bioquímicas, o soro. O controle da máquina era realizado por meio de sistema computacional no qual era possível observar se todas as amostras estavam sendo analisadas, caso algo estivesse incorreto, a máquina enviava um aviso sonoro e o computador apresentava mudança de cor (vermelho) nas determinadas cavidades que continham a amostra na qual observou-se o problema. As dosagens bioquímicas que deveriam ser realizadas eram identificadas pela máquina através da leitura de 
código de barras presentes nos tubos que eram adicionados ao equipamento.

Entretanto, algumas determinações, como cálcio ionizado, sódio e potássio não eram realizadas no BA-400 e sim em outro equipamento chamado de ionômetro, em que também utilizava-se o soro para as dosagens.

Finalizando as atividade neste setor, a última atribuição efetuada era o preparado da amostra de urina de $24 \mathrm{hs}$, em que basicamente retirava-se uma pequena alíquota da urina para posterior análise no BA-400 e fazia a medida do seu volume total para posterior desenvolvimento de cálculos.

\section{- Microbiologia}

No setor de microbiologia a rotina iniciava-se a partir da identificação das mais diversas amostras biológicas, destacando principalmente: urina $\mathrm{e}$ sangue. Após o registro dos dados do paciente (nome completo, ala e tipo de amostra), o material biológico era semeado em meios de cultura específicos.

$\mathrm{Na}$ urocultura, a urina era semeada com alça descartável de $0,001 \mathrm{~mL}$ a partir da introdução de uma linha reta no centro da placa, seguida do espalhamento da amostra com um séries de passagens usando um ângulo de $90^{\circ} \mathrm{em}$ meio CLED (para o crescimento de todos os microrganismos) e meio MacConkey (seletivo para bactérias Gram-negativas).

Após semeadura, as amostras eram incubadas a $37^{\circ} \mathrm{C}$ durante $24 \mathrm{hs}$. Ao término do tempo preconizado havia a contagem de colônias, em que valores superiores a $10^{5}$ Unidades Formadores de Colônias (UFC) eram indicativos de infecção, enquanto que valores inferiores a $10^{5}$ UFC indicavam a presença de contaminação. A urocultura é considerada como o padrão ouro para a confirmação de infecções do trato urinário, entretanto deve ser avaliada não só isoladamente, mas em conjunto com resultados do sumário de urina e a avaliação clínica feita pelo profissional médico ${ }^{13,14}$.

Para a hemocultura o procedimento era diferenciado, uma vez que, o sangue após ser coletado era rapidamente adicionado a um meio de cultura protegido por um suporte de vidro e contendo carvão ativado, que permitia a adsorção de antimicrobianos, trazendo assim mais confiabilidade aos resultados e evitando falsos negativos. Em seguida, as amostras eram armazenadas no equipamento Bact/Alert 3D-60, no qual após alguns dias o equipamento dava informações acerca de a cultura ser positiva ou negativa e se a bactéria encontrada era do tipo Gram-positiva ou Gramnegativa. Logo em seguida, as amostras de sangue positivas era semeadas, seguindo procedimentos semelhantes aos da urocultura, entretanto os meios de cultura utilizados eram Agar Sangue e Agar MacConkey. Depois de semeadas, as amostras eram armazenadas na estufa bacteriológica a $37^{\circ} \mathrm{C}$ por $24 \mathrm{hs}$ a $48 \mathrm{hs}$.
Para as demais amostras biológicas o semeio ocorria nos meios Agar Sangue e MacConkey ou ainda Agar Sabouroud Cloranfenicol, sendo este último utilizado em caso de suspeita de fungos; caso o material biológico fosse alguma secreção utilizavase o meio Stuart, para permitir o transporte até o laboratório e não haver a degradação da amostra.

De modo genérico, para toda e qualquer amostra biológica, após o período de incubação, aqueles meios de cultura que apresentassem crescimento teriam seu inóculo produzido com solução salina e verificado a partir do equipamento DensiCHEK plus. $\mathrm{Na}$ produção do inóculo, adicionava-se $3 \mathrm{~mL}$ de solução salina a $0,45 \%$ em dois tubos, no primeiro tubo adicionava-se partes da bactéria presente no meio de cultura até atingir uma turbidez que variasse entre 0,60 a 0,69 para Gramnegativos, 0,70 a 0,79 para Gram-positivos e 0,90 a 0,99 para fungos. Em seguida, caso fosse Grampositiva ou fungo retirava-se do primeiro tubo 280 $\mu \mathrm{L}$ e adicionava-se ao segundo tubo; caso fosse Gram-negativa retirava-se $145 \mu \mathrm{L}$ do primeiro tubo e colocava-se no segundo tubo. Depois do inóculo preparado os tubos eram levados ao equipamento VITEK 2, em que havia dois tipos de cartões distintos contendo um canudo. O primeiro cartão era usado para identificação da espécie e era adicionado ao primeiro tubo, de forma que o canudo entrasse em contato com o inóculo, enquanto que o segundo cartão era utilizado para verificar o perfil de sensibilidade do microrganismo e o mesmo procedimento era realizado. Após a alocação dos cartões junto aos tubos, estes eram adicionado ao VITEK 2, de forma que inicialmente tinha-se a sucção do conteúdo dos tubos para o interior do cartão, seguido da análise do equipamento que durava cerca de 48 horas para permitir a emissão dos resultados, no qual contemplava-se a espécie de bactéria ou fungo (e as vezes a subespécie), assim como, o antibiograma e qual o mecanismo de resistência era utilizado pela bactéria, caso se apresentasse resistente a algum fármaco.

Contudo, nem sempre o antibiograma era feito utilizando esse sistema, na falta de cartões para o VITEK 2, utilizava-se o método manual de KirbyBauer (difusão em disco) (Figura 3), que consistia em semear a amostra investigada em uma placa contendo o meio de cultura Müller-Hinton ${ }^{15}$. Logo após, adicionava-se discos contendo fármacos em diferentes localidades da placa de Petri, uma vez que, o princípio ativo se difunde radialmente, seguido de incubação a $37^{\circ} \mathrm{C}$ por cerca de $24 \mathrm{hs}$. Depois, fazia-se a análise através da medição do halo de inibição em milímetros e a partir daí determinava-se a sensibilidade dos microrganismos ao(s) fármaco(s) em questão.

No caso de bactérias resistentes ao imipeném outro teste era realizado, chamado de Teste de Hodge 
(Figura 4), justamente para saber se a bactéria era produtora de KPC (Klebsiella pneumoniae carbapenemase). Inicialmente, semeava-se, de preferência em Agar Müller-Hinton uma cepa padrão de Escherichia coli e no meio da placa adiciona-se um disco de imipeném, na qual a $E$. coli apresentavase sensível. Depois, semeava-se a bactéria suspeita de produzir KPC em diferentes quadrantes e em linha reta, de forma que as estrias eram feitas do centro do disco $\beta$-lactâmico até a periferia da placa. Caso o teste fosse negativo, observava-se a presença de um grande halo de inibição, indicando que a bactéria semeada não era produtora de KPC; caso fosse positivo o halo de inibição encontraria-se bastante reduzido, indicando que a bactéria suspeita transferiu a enzima KPC para a $E$. coli, conferindo a esta resistência ao imipeném ${ }^{16}$.
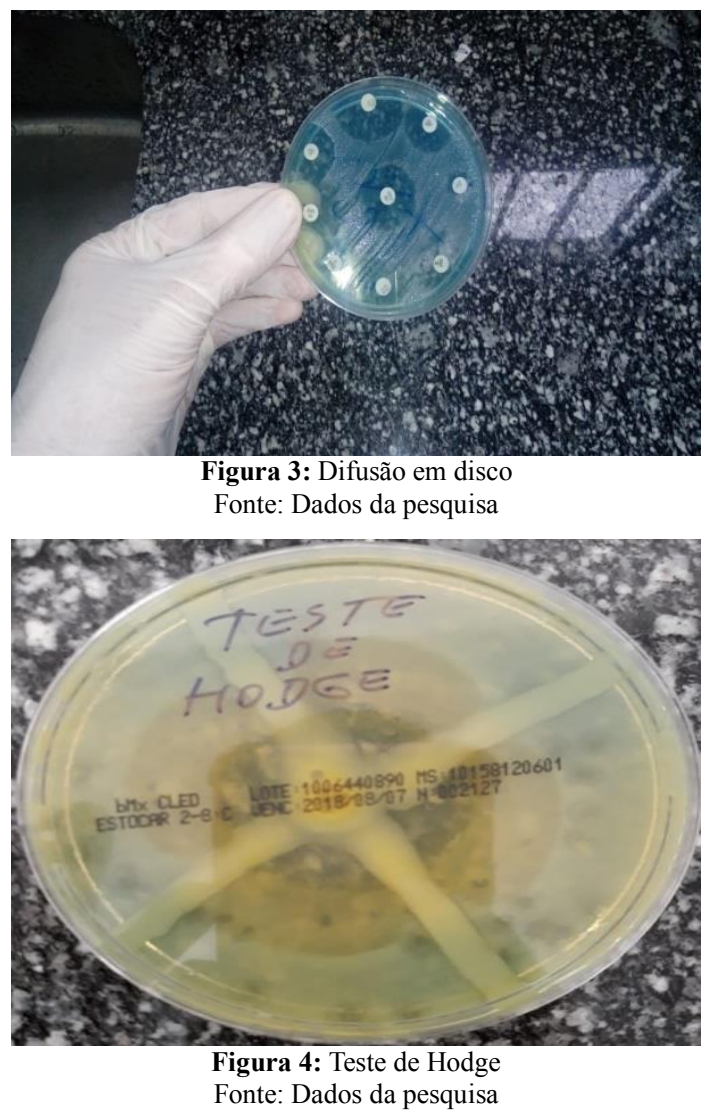

Amostras de escarro ou de sangue retirado de extremidades e lesões eram constantemente analisadas no laboratório de microbiologia para pesquisa de BAAR (bacilo álcool-ácido resistente) com o intuito de permitir o diagnóstico de tuberculose e hanseníase, respectivamente.

A pesquisa de BAAR era realizada a partir da coloração de Ziehl Neelsen. Inicialmente a amostra biológica deveria ser fixada na lâmina. Logo após, o esfregaço era coberto com Fucsina de Zielh durante 5 minutos e depois lavava-se a lâmina em água corrente. Em seguida, descorava-se a lâmina utilizando álcool-ácido resistente durante 2 minutos e logo após adicionava-se, o corante azul de metileno, durante 2 minutos. Por fim, a lâmina era lavada em água corrente e depois de seca o procedimento era finalizado com a leitura no microscópio óptico na objetiva de imersão de $100 \mathrm{x}^{17}$. O resultado positivo era observado a partir da presença de bacilos corados de rosa/vermelho. É interessante ressaltar que na microscopia é possível diferenciar Mycobacterium tuberculosis e M. leprae, devido esta última espécie bacteriana apresentar-se organizada em grumos (Figura 5).

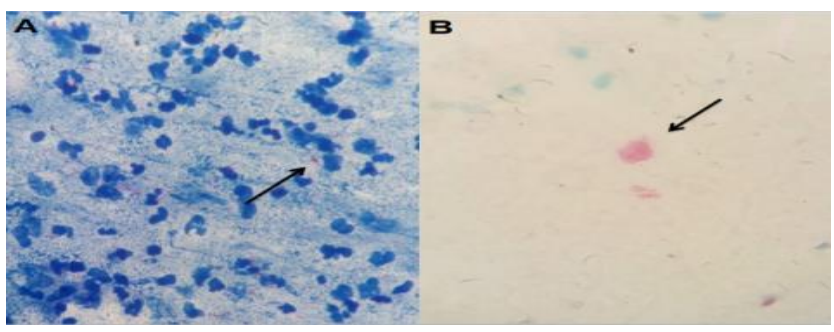

Figura 5: Mycobaterium tuberculosis (A) e M. leprae (B). Fonte: Dados da pesquisa

\section{- Hematologia}

As atividades no setor de hematologia iniciavam-se com a coloração de lâminas por meio de corantes de Romanovsky. $\mathrm{O}$ procedimento era iniciado a partir da adição de $500 \mu \mathrm{L}$ do corante sobre a lâmina durante 3 minutos, em seguida acrescentava-se $1000 \mu \mathrm{L}$ de água destilada e esperava-se mais 10 minutos. Ao fim do tempo estipulado as lâminas eram lavadas em água corrente, secas e depois levadas ao microscópio para serem lidas na objetiva de imersão de 100x. Caso fosse uma urgência, utilizava-se a coloração rápida a partir do corante panótico.

A contagem de reticulócitos, usada para o diagnóstico e monitorização de anemias e cânceres, também era realizada no setor de hematologia, porém cabia ao estagiário fazer somente $\mathrm{o}$ preparo da lâmina, em que o procedimento preconizado era adicionar $200 \mu \mathrm{L}$ do sangue total a um tubo, seguido de $200 \mu \mathrm{L}$ do coral azul de crisel brilhante. Em seguida, a amostra era levada ao banho-maria durante 30 minutos a $37^{\circ} \mathrm{C}$. Depois do tempo preconizado a amostra era retirada e uma alíquota de cerca de $10 \mu \mathrm{L}$ era adicionada a um lâmina, logo após fazia-se o esfregaço, esperava-se secar e a leitura era realizada na objetiva de imersão de $100 x^{18}$.

O VHS (Velocidade de Hemossedimentação) também era feito pelo estagiário. Este teste consiste em observar a velocidade de sedimentação das hemácias, avaliada em milímetros, pela separação dos glóbulos vermelhos do plasma. Esse ensaio era realizado a partir da adição do sangue total em um suporte de vidro demarcado em milímetros, permitindo a sua contagem após 1hora da adição do material biológico. VSH é utilizado, principalmente, no diagnóstico e no acompanhamento clínico de doenças como a artrite reumatóide, o lúpus eritematoso sistêmico e a doença reumática, sendo que em adultos, os valores normais para o sexo 
masculino são aqueles menores que $10 \mathrm{~mm}$ e para o sexo feminino menores de $20 \mathrm{~mm}^{19}$.

A última atribuição do estagiário realizado no setor de hematologia era a dosagem do TP (tempo de protrombina) e TTPA (tempo parcial de tromboplastina ativada), a partir do uso do equipamento CoL4. Para o TP adicionava-se a um tubo $50 \mu \mathrm{L}$ do soro paciente e incubava-se no equipamento por 60 segundo, após o tempo preconizado adicionava-se $100 \mu \mathrm{L}$ do reagente TP e esperava a emissão do resultado. No caso do TTPA adicionava-se a um tubo $50 \mu \mathrm{L}$ do soro do paciente mais $50 \mu \mathrm{L}$ do reagente TTPA, após 180 segundo de incubação adicionava-se cloreto de cálcio e esperavase pelo resultado. Quando os resultados eram considerados superiores ou inferiores a normalidade, havia a repetição para posterior confirmação e liberação dos resultados.

- Coleta

O setor de coleta foi dividido em dois momentos distintos: coleta de pacientes internos e coleta de pacientes ambulatoriais. $\mathrm{Na}$ coleta de pacientes internos, devido maior dificuldade de coleta e o curto tempo, a experiência adquirida foi basicamente observacional. Enquanto que no ambulatório, foi possível fazer a realização de coleta endovenosa, tempo de sangria (TS) e tempo de coagulação (TC).

Antes da coleta propriamente dita, havia a recepção do paciente, em que neste momento, a identificação, os exames e os tubos nos quais seriam depositadas as amostras biológicas eram conferidos. Em seguida, havia o posicionamento do braço em linha reta, para permitir maior conforto ao paciente e maior acessibilidade as veias. Depois, tinha-se o garroteamento justamente para facilitar a localização das veias devido deixá-las mais proeminentes. Logo após, havia a seleção da região de punção através da aferição visual ou apalpação das veias elegendo-se as mais calibrosas e por fim, o sangue era coletado e transferido aos tubos que poderiam conter ou não anticoagulantes $^{20}$.

O TC era avaliado a partir da contagem do tempo em que o sangue necessitava para coagular. Dessa forma, o sangue extraído era adicionado a um tubo previamente identificado, em seguida colocavase no banho-maria a $37^{\circ} \mathrm{C}$, sendo que a contagem do tempo era iniciada logo após a retirada do sangue do paciente. A partir de cinco minutos, começava-se a verificar a cada 30 segundos, vertendo-se o tubo, e observando se o sangue havia coagulado. Tal teste é importante, uma vez que, diversas coagulopatias como hemofilia A e B e doença de Von Willebrand, apresentam o TC elevado ${ }^{21}$.

O tempo de sangria (TS), por sua vez, é um teste laboratorial realizado in vivo que avalia a função hemostática das plaquetas, vasos e o fator de Von Willebrand. Conceitualmente, o TS se refere ao tempo de duração do sangramento de uma pequena incisão provocada com o auxílio de uma lanceta ${ }^{22}$. Durante o estágio, a lanceta era utilizada para perfurar o lóbulo da orelha e a partir de um minuto iniciava-se a aferição do sangramento por meio de um papel absorvente. Em seguida, após o primeiro minuto as aferições eram repetidas a cada 30 segundos.

Por fim, após a coleta de sangue e/ou análise de TS e TC os valores encontrados eram computados e o sangue coletado era devidamente adicionado em tubos específicos e o próximo paciente era convidado a sala de coleta.

Dessa forma, a partir das atividades descritas neste relato de experiência é possível evidenciar que em análises clínicas o conhecimento teórico é insuficiente para permitir que o profissional farmacêutico atue na área, reforçando, portanto, a importância do estágio obrigatório. Ademais, este trabalho pode servir para guiar outros estudos que tenham essa mesma temática como foco centralizador, servir como material de estudo/apoio aos estudantes de farmácia ou ainda ser útil para o embazamento de trabalhos desenvolvimentos dentro do âmbito das análises clínicas.

CONCLUSÃO

O estágio em análises clínicas se mostrou de grande importância ao graduando em farmácia, uma vez que, possibilitou por em prática os conhecimentos teóricos adquiridos anteriormente. Ademais, permitiu maior confiança no manejo de instrumentos laboratoriais e aquisição de novas informações sobre as áreas de hematologia, urinálise, microbiologia, bioquímica e coleta. Entretanto, devido a abrangência de áreas contidas nas análises clínicas a busca por cursos de pós-graduação e/ou capacitação tornam-se interessantes.

\section{REFERÊNCIAS}

1. UFCG. Universidade Federal de Campina Grande. Resolução no: 08/2009. 2009. Disponível em:< http://www.ufcg.edu.br/ costa/resolucoes/res_160 82009.pdf>. Acesso em: 22 jun. 2018.

2. CFF. Conselho Federal de Farmácia. Formação do farmacêutico para o exercício das análises clínicas e o título de farmacêutico bioquímico. 2010. Disponível em:< http:/www.cff.org.br/sistemas/ geral/ revista/pdf/125/016_artigo_lenira.pdf $>$. Acesso em: 04 ago. 2018.

3. CRF-PR. Conselho Regional de Farmácia do Paraná. Comissão de Análises Clínicas. 2018. Disponível em:< http://www.crf-pr.org. br/site/ comissao/visualizar/id/4/Analises-Clinicas> Acesso em: 22 jun. 2018.

4. CRF-PR - Conselho Regional de Farmácia do Paraná. O Farmacêutico Bioquímico e seu papel na Assistência Farmacêutica: um caso de infecção pelo HIV-2 em Curitiba. 2013. Disponível em:< 
http://crf-pr.org.br/uploads/noticia/13030/o farmaceutico_bioquimico_MENCAO_HONROS A.pdf>. Acesso em: 04 ago. 2018.

5. UFCG. Universidade Federal de Campina Grande. HUAC se torna o primeiro hospital pública de Campina Grande a possuir tomógrafo computadorizado. 2008. Disponível em:< http://www.dsc.ufcg.edu.br/ pet/jornal/julho2008/ materias/ufcg.html >. Acesso em: 25 de fevereiro de 2018.

6. Andrade Júnior FP, Barbosa, VSA. Monitoria acadêmica em parasitologia humana: um relato de experiência. Rev Saúde Com. 2017;13(3):972-75.

7. Mota CL, Beça HP. Análise sumária de urina de rotina: porquê e para quê?. Rev Port Med Geral Fam, 2013;29(4):244-48.

8. Heggendornn LH, Silva NA, Cunha GA. Urinálise: a importância da sedimentoscopia em exames físico-químicos normais. REB. 2014;7(4):431-43.

9. Altenburg FL, Biondo-Simões MLP, Santiago A. Pesquisa de sangue oculto nas fezes e correlação com alterações nas colonoscopias. Rev bras coloproctol. 2007;27(3):304-9.

10.Jatobá MP, Candelária PAP, Klug WA, Fang CB, Capelhuchnik P. Pesquisa de sangue oculto nas fezes e chado colonoscópico em 60 pacientes. Rev bras. Colo-proctol., 2008, 28(4):425-30.

11.USP. Universidade de São Paulo. Coleta de sangue/flebotomia. 2017. Disponível em:< https://edisciplinas.usp.br/pluginfile.php/2877661/ mod_resource/content/1/Coleta\%20de\%20Sangue $\% 202017$.pdf>. Acesso em: 23 jun. 2018.

12. Berlitz FA. Controle da qualidade no laboratório clínico: alinhando melhoria de processos, confiabilidade e segurança do paciente. J Bras Patol Med Lab. 2010;46(5):353-63.

13. Carvalhal GF, Rocha LCA, Monti PR. Urocultura e exame comum de urina: considerações sore sua coleta e interpretação. Rev AMRIGS. 2006; 50(1):59-62.

14. Santos Filho L. Manual de microbiologia clínica. João Pessoa: Universitária; 2006.

15.Wachino JI, Kimura K, Yamada K, Jin W, Arakawa Y. Evaluation of Disk Potentiation test using kirby-bauer disks containing high-dosage fosfomycin and glucose-6-phosphate to detect production of glutathione s-transferase responsible for fosfomycin resistance. J Clin Microbiol., 2014, 52(10):3827-828.

16.ANVISA. Agência Nacional de Vigilância Sanitária. Teste de sensibilidade aos antimicrobianos. 2008. Disponível em: $<$ http://www.anvisa.gov.br/servicosaude/controle/re de_rm/cursos/boas_praticas/modulo5/gram_negati vos8.htm>. Acesso em: 04 ago. 2018.

17.UFJF. Universidade Federal de Juiz de Fora. Técnicas de coloração comuns na bacteriologia.
2018. Disponível em:< http://www.ufjf.br/ microbiologia/ files/2018/04/ROTEIRO-PARAAULAS-PR\%C3\%81TICAS-bacteriologia-2018parte-03-Tecnicas-de-colora $\% \mathrm{C} 3 \% \mathrm{~A} 7 \% \mathrm{C} 3 \%$ A3 o.pdf $>$. Acesso em: 24 nov. 2018.

18. Miyake CET. Reticulócitos: da contagem manual à citometria de fluxo [monografia] Curitiba: Universidade Federal do Paraná - UFPR; 2011.

19. Santos VM, Cunha SF de C, da Cunha DF. Velocidade de sedimentação das hemácias: utilidade e limitações. Rev Assoc Med Bras. 2000;46(3):232-36.

20.UFSC. Universidade Federal de Santa Catarina. Guia prático para coleta de sangue. 2013. Disponível em: $<$ http://lidoc.ccb.ufsc.br/files/ 2013/10/Guia_de_Coleta_de_Sangue.pdf $>$.Acesso em: 04 ago. 2018 .

21.UFERSA. Universidade Federal Rural do Semiárido. Avaliação da hemostasia. 2009. Disponível em: $<$ http://www2.ufersa.edu.br/ portal/view/uploads/setores/181/arquivos/ Hemostasia2.pdf>. Acesso em: 04 ago. 2018.

22. Brasil. Ministério da Saúde. Manal de Diagnóstico Laboratorial das Coagulopatias Hereditárias e Plaquetopatias. 2010. Disponível em: $<$ http://bvsms.saude.gov.br/bvs/publicacoes/ manual_diagnostico_laboratorial_coagulopatias_p laquetopatias.pdf>. Ácesso em: $0 \overline{5}$ ago. 2018.

\section{CONFLITO DE INTERESSES}

Os autores declaram não haver conflitos de interesse.

\section{AUTOR PARA CORRESPONDENCIA}

Francisco Patrício de Andrade Júnior

juniorfarmacia.ufcg@outlook.com

Submetido em 27/11/2018

Aceito em 12/03/2019 